\title{
Introduction over Newly-Discovered Petroglyphs of Tang-e Birzal, Southern Iran
}

\author{
Soraya Estavi', Zahra Asghari², Ali Aarab³, Reza Rezaloo', Aliye Amirinejad ${ }^{4}$ \\ ${ }^{1}$ Department of Archaeology, University of Mohaghegh-e Ardebili, Ardebil, Iran \\ ${ }^{2}$ Department of Archaeology, Islamic Azad University, Tehran, Iran \\ ${ }^{3}$ Department of Archaeology, University of Tehran, Tehran, Iran \\ ${ }^{4}$ Department of Archaeology, University of Sistan \& Baluchestan, Zahedan, Iran \\ Email: ali.aarab@ut.ac.ir
}

Received 27 April 2016; accepted 6 June 2016; published 9 June 2016

Copyright (C) 2016 by authors and Scientific Research Publishing Inc.

This work is licensed under the Creative Commons Attribution International License (CC BY).

http://creativecommons.org/licenses/by/4.0/

(c) (i) Open Access

\begin{abstract}
The newly-discovered petroglyphs (at Tang-e Birzal) have located at a mountainous area, in 26 kilometers away from the northeastern point of Kohgiluye va Buier Ahmad Province, in pursuant of a nomadic trek road, and near Mondan village at Sarfaryab district of Charam town. These reliefs were found by a field consideration in 2013, but they have not introduced yet. These reliefs and drawings in this site (Tang-e Birzal) are divided into two categories: Geometric and Animal. The geometric reliefs and drawings have smallest number. These samples are like symbolic and meaningless signs and a personal name that has been possibly craved in the recent years. The animal reliefs and drawings like mountain goat have been created in the different sizes. These reliefs have been shallowly craved on the two lime rocks with the 5 meters away from each other. But some of these drawings have deeply carved at the first complex. These samples bring some questions to mind about their creators and their era and what kind goal has been behind them? $A$ comparison between the petroglyphs' chronicle accrued to the Tang-e Birzal and other samples in the various points of Iran shows that some of these petroglyphs are related to the $2^{\text {nd }}$ Iron Era (based on their carving type and morphology) and that some other samples are associated to the history period. This paper is aimed to consider the complex 1 and 2, their structural style, artistic motifs, pictures and their related era.
\end{abstract}

\section{Keywords}

Petroglyphs, Kohgiluye va Bouier Ahmad, Ibex Drawings, Tang-e Birzal

\section{Introduction}

Rock art: petroglyphs or rock arts are oldest historic and artistic samples that have remained from the history of

How to cite this paper: Estavi, S., Asghari, Z., Aarab, A., Rezaloo, R., \& Amirinejad, A. (2016). Introduction over NewlyDiscovered Petroglyphs of Tang-e Birzal, Southern Iran. Archaeological Discovery, 4, 119-124. 
human being. In other words, these stones were milestone to create secret words, script and also exchange of message, history, legend, art and culture, in fact these stones reliefs are best instruments to discover the prehistoric eras, then any drawings on the stone could be named as the stone relief or rock art. The rock art has a global category that can be adopted over the Iranian samples too.

In the two recent decades, the rock art as a global matter has been drawn attention in Iran (Karimi, 2007). The rock reliefs and rock carvings have named as the rock art or archaeology of the rock art by the archaeologists and other related experts. Their origin place is mountainous areas as their names point out us. Their morphology is graphical and simple (Molla Salehi et al., 2007). The rock reliefs have pictured the scenes like hunting, fight and a picture of the mountain goat, in fact they have created by the hitting method. It means that these shallow drawings have created on the stones by the various hitting devices. The subjects of these petroglyphs have obtained from the conditions of the same area such as environment, culture and geography. Today, rock drawings are known a long standing art, since this art has been lasted from the Paleolithic era to the contemporary era. Then, this concept and the ancientness must be identified. Therefore, this field should be investigated the various matters like archaeology, anthropology, art and semiotics (Rezaee \& Joudi, 2010: p. 13). The main subjects in these pictures are a folk of the mountain Ibex, equestrians with the bows or individual Ibex.

Despite to so many objective studies about the rock drawings in India, middle Asia, caucuses, and even introducing a new scientific field to study over the rock reliefs, but this scope has not still drawn attention of the foreign and domestic researchers, as such that our knowhow about the different aspects of these samples is minimal and also many questions in this field left unanswered. While, this huge number of the rock reliefs in the various places of Iran can clearly indicate that Iran has at least a similar status like the Asian territories (Ghasrian, 2007).

The Italian researchers are known as the first group who start to investigate on this field in Iran. When a group of the Italian geologists (1958) were working to excavate the mineral materials in Baluchestan, they found some rock reliefs in Gazo area (Dessau, 1960). These samples are known as the first discovered rock reliefs (Ghasrian, 2007: p. 19) in Iran. The preliminary report of McBorni about the rock reliefs in Doshe and Mir Melas (1969) was the first report on Iranian rock reliefs. One of the most important samples between the Iranian petroglyphs is Teimareh that also a comprehensive book about this place has been compiled in 1998 (Farhadi, 1998: pp. 65-66). In 2005, Jalal Rafi' Far in his book titled "petroglyphs of Arasbaran" has more comprehensively considered the samples in Horand of Kaleibar (Laqan) (Raf'iFar, 2005). Shahram Zare et al. published an expertise magazine in 2007. This magazine includes the newest results from the Iranian rock reliefs and drawings (2007, No. 3). The reliefs at theTang-e Birzal due to their concept, style and method have a similarity with the other samples in Meimand Village (Karimi, 2007), Uraman (Qassimi, 2007), Sangestoon (Ghasrian, 2007), Khare Hanjiran (Ghasrian \& Naderi, 2007), Azandaryan (Hemati Azandaryani et al., 2014) main shelter of Horand and Songon (Raf'i Far, 2005), Complex B of Orges Sofla (Beik Mohammadi et al., 2012), Kurdistan (Lahafian, 2004; 2006; 2010), and Shamsali and Gorgali Rock Shelters in Kohgiluye va Bouier Ahmad (Hemati Azandaryani et al., 2015).

There have not been studies about the petroglyphs in Kohgiluye va Bouier Ahmad Province, and this study is the first one, but we have some questions about the Tang-eBirzal: who are the artists of these reliefs and these reliefs are accrued to which era? Why these reliefs have not any drawing's detail and perspective? These reliefs have originated from items like livelihood, geographic and cultural situations (such as many folks of the mountain Ibex). Consideration about these petroglyphs is a prelude to a complete knowhow over the some concepts related to the anthropology and sociology. For example, these reliefs have a common language to introduce the most valuable beliefs like the role of goat itself and goat hunting in the nomadic life or a life on basis of hunting and animal husbandry, but more important matter is, these reliefs have pictured via a simple manner. These reliefs have concentrated on a range of the simple matters like pastoral life and trek. These pictures have been drawn at the open places, then they have experienced the corrosion made by precipitations, and dissolving the existed salt in the stone once crack and blast on the stone are created, hence all these events have caused a series of the changes in their physical and chemical features and if the same trend is continued, then we can witness more dire consequences on them.

\section{Site Location}

Geographic and spatial status of the petroglyphs accrued to the Tang-e Birzal is located in Kohgiluye va Bouier 
Ahmad Province-its central capital "Yassoj” —in 3043'42.70"N and 50 $50^{\prime} 12.30 " E$ this site has an estimated measurement of 16,249 cubic kilometers, in fact this sites mostly mountainous because this province has located in the southwestern Iran and also this province has 5 neighbors as follow; Isfahan, Fars, Boushehr, Khozestan and Chahar Mahal va Bakhtiari Provinces. Moreover, this area has always been known as a residential area. This area has so many precious and seeable places with ancientness around the thousand years that they are accrued to the Elamite, Achaemenian, Parthian and Sassanid tribes And up to the contemporary era. This site (Tang-e Birzal) has located in Charam town of Kohgiluye va Bouier Ahmadand its exact geographical status becomes the 24 kilometers away from the Sarfaryab-Dehdasht road, in fact these reliefs are locatedat the Sarfaryab district and Mondan village.

\section{Research Method}

The research method has performed based on the two approaches; field and library. In the field approach, a field consideration has been performed to find this place, then reliefs were photographed and also all spatial data were collected by GPS, and also all reliefs are designed by the Photoshop and Corel Drawing. In the library approach, we had a prevalent study and comparison between these samples and the similar ones (Figure 1).

\section{The Petroglyphs of Tang-e Birzal, Complex 1}

On the a brown-orange limy boulder with the 3 meter height, there are many mountain Ibex as the folk or indi-

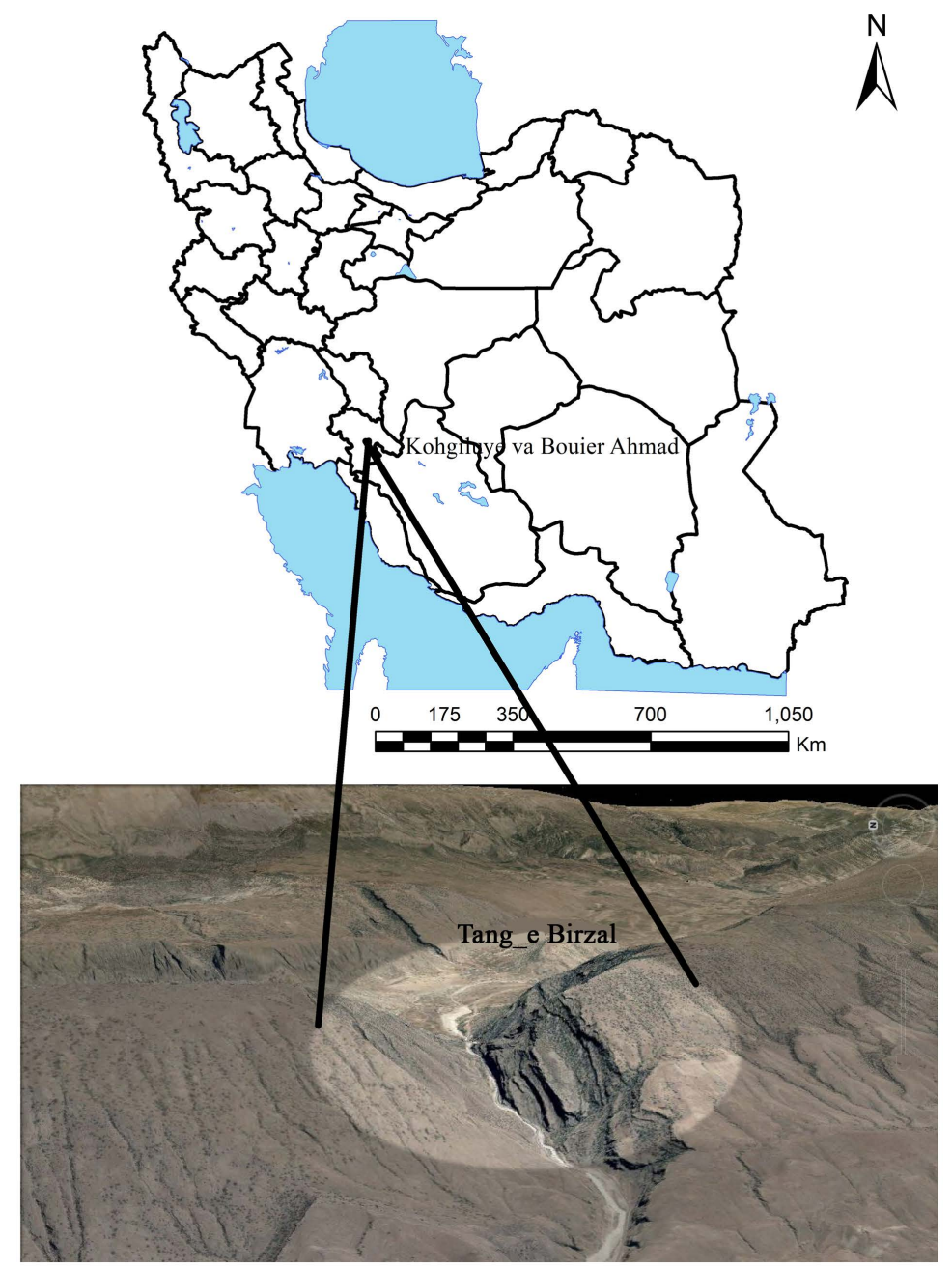

Figure 1. The Location of rock art in Tang-e Birzal, Kohgiluye va Bouier Ahmadand, Iran. 
vidual, but this boulder has been damaged by the precipitations. This boulder with the pictures of the Ibex, could remind the height habitats of the same animal. These reliefs have located in the lowest part of this boulder in a form that the last goat is $10 \mathrm{~cm}$ away from the earth. These Ibex have been morphologically pictured in the different positions and shapes, and also they have been drawn with the various horns and body status. These reliefs have an abstraction style, since they are only a series of the simple lines, in other words, shape of this animal has been drawn based on the same simple lines. There is not any sign of the 3D reliefs at all, in fact these samples have craved with the simplest lines. The Ibex have shown in a profile form, and these Ibex have extraordinary horns because these horns are even longer than their bodies and some horns have continued through their tiny reverse-up tails. These reliefs are not dynamic, maybe this static manner is related to a static scene of the grazing Ibex in the meadow. This complex has 18 (craved) mountain Ibex, but we can't count their exact number, because backdrop of the reliefs has corroded. The six samples have a $1 \mathrm{~cm}$ depth and there have been the stony and metal devices to create these reliefs as such that these reliefs have created by the repeated scratching on the stones-by the same stony or metal devices. In other words, a superficial layer has separated from the main or depth layer. These reliefs are accrued to the $2^{\text {nd }}$ Iron Era or history period, and they have possibly been created by the metal devices since they are other similar samples in the other places of the country. Many of the Ibex direct toward the south (hung down heads) and other ones have could have been created by the hitting style since they have not a considerable depth and volume. These Ibex have linear shape in their body, hands and feet, and their heads fell hang down and have a reverse up tail, but we can see the similar samples in the other places of the country. Hence, these reliefs could remind us the mountain goat picture on the clay bowels discovered in Shush and Shahr-e Sokhteh. The other reliefs which as if have been newly created, in fact they are meaningless and also a personal name (Masood) that has possibly craved by a visitor or tourist (Figure 2 and Figure 3).

\section{The Petroglyphs of Tang-e Birzal, Complex 2}

In a 5 meters away from the complex 1, there is another brown-orange rock with the goat picture again, but its face has severely damaged as such that its reliefs have disintegrated, nevertheless we can see a folk of the mountain Ibex. These reliefs are like reliefs of the complex 1, but these samples have longer ancientness. In fact, these reliefs have created by the scratching or hitting styles and they have a $1-2 \mathrm{~mm}$ depth and $0.5-2 \mathrm{~cm}$ width. These Ibex have linear hands and feet, longed bodies, bow-like and big horns, hung down heads and face toward to the southern point. It is worthy to note that the two Ibex are bigger than other ones, this maybe has a special concept or the artist would like to make a variety (Figure 4).
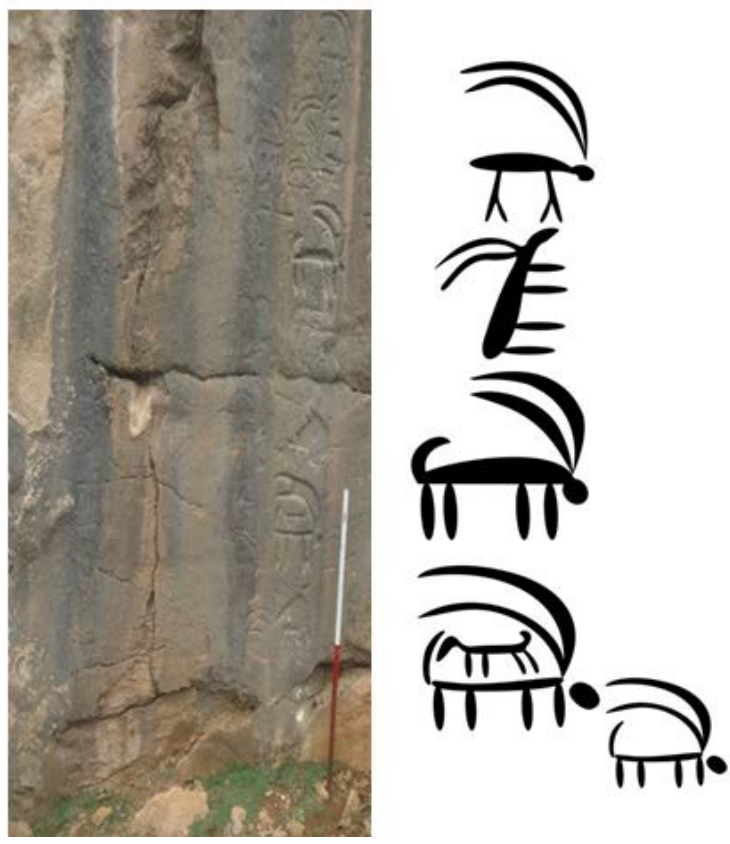

Figure 2. Ibexes in complex 1 at Tang-e Birzal. 


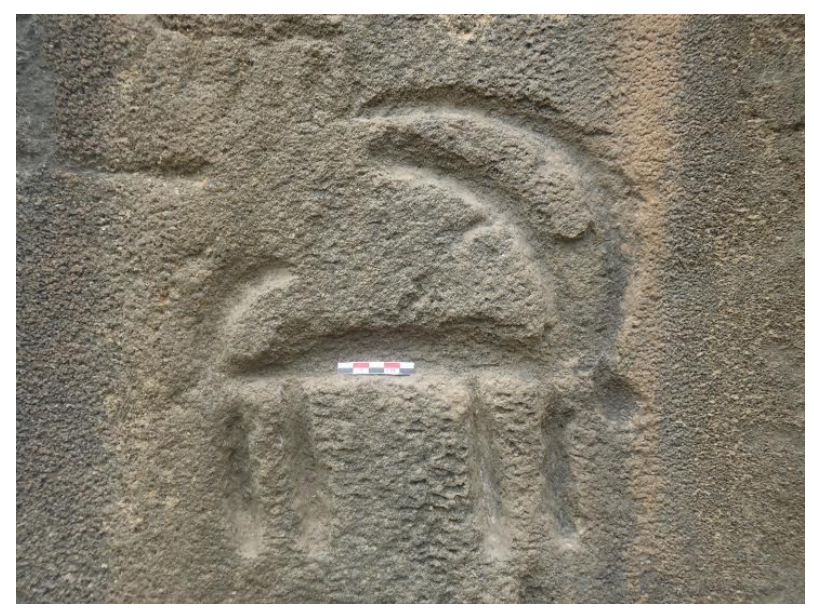

Figure 3. Ibex in complex 1.

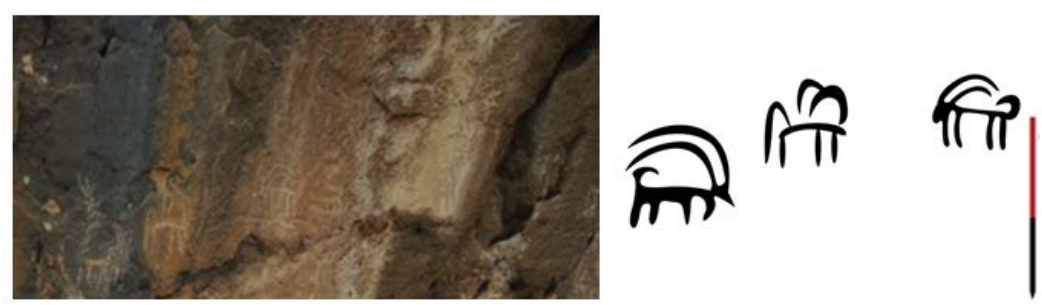

Figure 4. Ibexes in complex 2 of Tang-e Birzal.

\section{Conclusion}

An inner drive has converted a hunting human to an artist one, one who its cravings has aesthetically been attracted so many researchers. In this artistry, the animals are a concept-carrier instrument or the human would use them to construct the legendary mixes. A legend has been converted the human to a master artist. This artist has selected the rocks as its canvas, the stones and metal as its pen. In fact, these pictures would have been engraved in the mind of hunting human. Then, its real device could be known as reflection of thoughts. These thoughts have accrued to the nature and ecology, one human who its life has depended to the presence of the same goat. Then, goat hunting is like the wheat for the farmer, because both save the life of human being. The reliefs of Tang-e Birzal are Petroglyph or craving and also they have created by the hitting style. These reliefs are geometric or symbolic and animal. Around the complex 1 and complex 2, there wasn't any other type of rock with pictures.

These samples have experienced the different corrosions and chemical transformations. All these events have led to the physical and chemical changes on these craved samples as well. An important matter about these reliefs is that there are numerous long and bow-like horny Ibex as the folk or individual.

\section{References}

Beik Mohammadi, K. H., Janjan, M. \& Beik Mohammadi, N. (2012). Introduction and Analysis of New Found Petrography Motif of B Set of Sofla Arges (Malayer-Hamedan). Faculty of Art and Architecture Department of Archaeology, 2, 121140.

Farhadi, M. (1998). Newly-Discovered Rock Reliefs in Sirjan and Shahr-e Babak in Kerman. Cultural Heritage, 17, 12-19.

Ghasrian, S. M. (2007). Introducing the Carvings of Sangestoon in Center Plateau of Iran. BastanPazhohi, 2, 85-89.

Ghasrian, S. M., \& Naderi, R. (2007). Considering Rock Reliefs in Khare Hanjiran, Mahabad. BastaPazhohi, 2, 61-64.

Hemati Azandaryani, E., Qolami, H., MohammadiFar, Y., \& Razmposh, A. (2015). Discovering New Rock Paintings at Shmsali and Gorgali Rock Shelters in Kohgiluye and Bouier Ahmad Province, Southern Iran. Arts, 4, 61-67.

Hemati Azandaryani, E., Mohamadifar, Y., Hejebri Nobari, \& Khanali, H. (2014). Azandaryan: Newfound Petroglyphs in Hamadan, Western IRAN. Rock Art Research, 31. (In press). 
Karimi, F. (2007). A New Insight into the Rock Engravings of Iran Based on Field Investigations. Bastanpazhuhi, $2,20-34$. (In Persian).

Lahafian, J. (2006). The Honorable Head of Iran's Cultural Heritage Archaeology and Tourism. IFRAO Report, IFRAO Global State of the Art with the UISPP 15th Congress, Lisbon, 9 September 2006, 36.

Lahafian, J. (2004). Petroglyphs of Kurdistan. Rock Art Research, 21, 3-10.

Lahafian, J. (2010). Cupules in Kurdistan Rock Art. Rock Art Research, 27, 177-183.

Molla Salehi, H., Saed Pur, M., Momeni, A., \& Bahram Zadeh, M. (2007). Archaeology of Rock Reliefs in South Qazvin. BastanPazhohi, 2, 35-45.

Qassimi, T. (2007). A Report of Considering the Rock Reliefs in Uraman Area. BastanPazhohi, 2, 71-80 (in Persian).

Rezaee, M., \& Joudi, Kh. (2010). Holosh Reliefs, Analyses and Chronicle, Site of Scientific Magazine of Humanism and Culture. www.Anthropology.ir 